\title{
Theoretical studies of energy levels and transition data for $\mathrm{Zr} \mathrm{III}{ }^{\star}$
}

\author{
P. Rynkun ${ }^{1}$, G. Gaigalas ${ }^{1}$, and P. Jönsson ${ }^{2}$ \\ ${ }^{1}$ Institute of Theoretical Physics and Astronomy, Vilnius University, Saulètekio av. 3, 10222 Vilnius, Lithuania \\ e-mail: pavel.rynkun@tfai.vu.1t \\ ${ }^{2}$ Group for Materials Science and Applied Mathematics, Malmö University, 20506 Malmö, Sweden
}

Received 3 December 2019 / Accepted 6 March 2020

\begin{abstract}
Aims. We seek to present accurate and extensive transition data for the $\mathrm{Zr}$ III ion. These data are useful in many astrophysical applications.

Methods. We used the multiconfiguration Dirac-Hartree-Fock and relativistic configuration interaction (RCI) methods, which are implemented in the general-purpose relativistic atomic structure package GRASP2018. The transverse-photon (Breit) interaction, vacuum polarization, and self-energy corrections are included in the RCI computations.

Results. Energy spectra were calculated for the 88 lowest states in the $\mathrm{Zr}$ III ion. The root-mean-square deviation obtained in this study for computed energy spectra from the experimental data is $450 \mathrm{~cm}^{-1}$. Electric dipole (E1), magnetic dipole (M1), and electric quadrupole (E2) transition data, line strengths, weighted oscillator strengths, and transition rates are computed between the above states together with the corresponding lifetimes. The computed transition rates are smaller than the experimental rates and the disagreement for weaker transitions is much larger than the experimental error bars. The computed lifetimes agree with available experimental values within the experimental uncertainties.
\end{abstract}

Key words. atomic data

\section{Introduction}

Zirconium is an important element in stellar spectroscopy and in studies of s-process nucleosynthesis in HgMn type stars. The spectral lines of $\mathrm{Zr}$ III have been observed in the chemically peculiar B-type star Chi Lupi with the Goddard high-resolution spectrograph on the Hubble Space Telescope (Leckrone et al. 1993). By determining the zirconium abundance in this star from weak Zr II optical and from strong Zr III ultraviolet (UV) spectral lines, a significant difference was found (Sikström et al. 1999; Leckrone et al. 1993). Pandey et al. (2004) observed that the abundances of heavier elements (including $\mathrm{Zr}$ ) for two hot extreme helium (EHe) stars, V1920 Cyg and HD 124448, strikingly differ. Castelli et al. (2017) performed an abundance analysis from a UV spectrum of the HR 6000 star and pointed out that the abundance of some elements in this star contrasts with the usual overabundance in $\mathrm{HgMn}$ stars.

Atomic data (energy levels, transition data) of the $\mathrm{Zr}$ III ion presented in the Atomic Spectra Database (ASD) of the National Institute of Standards and Technology (NIST; see Kramida et al. 2019) are based on the results from Reader \& Acquista (1997). Reader \& Acquista (1997) measured lines of the Zr III ion with sliding spark discharges on the normal-incidence vacuum spectrograph and classified 482 transitions. These authors also calculated oscillator strengths and transition rates for all of the classified lines using fitted energy parameters.

Redfors (1991) used the Cowan code to compute oscillator strengths. Charro et al. (1999) calculated oscillator strengths employing the relativistic quantum-defect orbital (RQDO)

\footnotetext{
* Table 4 is only available at the CDS via anonymous ftp to cdsarc.u-strasbg.fr (130.79.128.5) or via http://cdsarc. u-strasbg.fr/viz-bin/cat/J/A+A/637/A10
}

method. Beck \& Pan (2004) presented energy levels, oscillator strengths, and Landé factors for some $J=0,1$ states of the $\mathrm{Zr}$ III and $\mathrm{Nb}$ IV using the relativistic configuration interaction (RCI) method. Martins et al. (2006) calculated oscillator strengths for $4 \mathrm{~d} 4 \mathrm{f}-4 \mathrm{~d}^{2}$ transitions using the multiconfiguration Dirac-Hartree-Fock (MCDHF) method with quantum electrodynamic (QED) corrections.

There are only a few experimental works presenting lifetimes or radiative transition rates for the $\mathrm{Zr}$ III ion. Mayo et al. (2005) determined transition probabilities for 120 lines using the laser-induced break-down spectroscopy (LIBS) method. The rates were obtained from branching ratio measurements and by using theoretical lifetimes, line-strength sum rules, and Boltzmann plots. Later, Mayo et al. (2006) measured lifetimes of five levels of the $4 \mathrm{~d} 5 \mathrm{p}$ configuration.

In the present work ab initio calculations were performed for the 88 (40 even and 48 odd) lowest states in the $\mathrm{Zr}$ III ion. Energy levels, electric dipole (E1), magnetic dipole (M1), and electric quadrupole (E2) transition data were computed along with the corresponding lifetimes of these states. The computations were done using the general-purpose relativistic atomic structure package GRASP2018 (Froese Fischer et al. 2019).

\section{Method}

\subsection{Computational procedure}

The GRASP2018 package used for the computations is based on the MCDHF and RCI methods. More details about these methods can be found in Froese Fischer et al. (2016) and Grant (2007).

In the MCDHF approximation, atomic state functions (ASFs) are given as linear combinations of symmetry adapted 
Table 1. Summary of active space construction strategies used in this work.

\begin{tabular}{lcccc}
\hline \hline \multirow{2}{*}{ Strategy } & OS & Inactive core & \multicolumn{2}{c}{$N_{\text {CSFs }}$} \\
\cline { 4 - 5 } & & & Even & Odd \\
\hline VV & $\mathrm{AS}_{4}$ & {$[\mathrm{Kr}]$} & 2078 & 2256 \\
VV+CV & $A S_{4}$ & {$[\mathrm{Ar}] 3 d^{10}$} & 349894 & 464978 \\
VV+CV+CC & $\mathrm{AS}_{4}$ & {$[\mathrm{Ar}] 3 d^{10}$} & 7252853 & 10258516 \\
VV+CV+CC+extended MR & $\mathrm{AS}_{4}$ & {$[\mathrm{Ar}] 3 \mathrm{~d}^{10}$} & 10870442 & 12661982 \\
VV+CV+CC+extended MR & $\mathrm{AS}_{5}$ & {$[\mathrm{Ar}] 3 \mathrm{~d}^{10}$} & 14255953 & 16514844 \\
\hline
\end{tabular}

Notes. $N_{\mathrm{CSF}}$ is the number of CSFs.

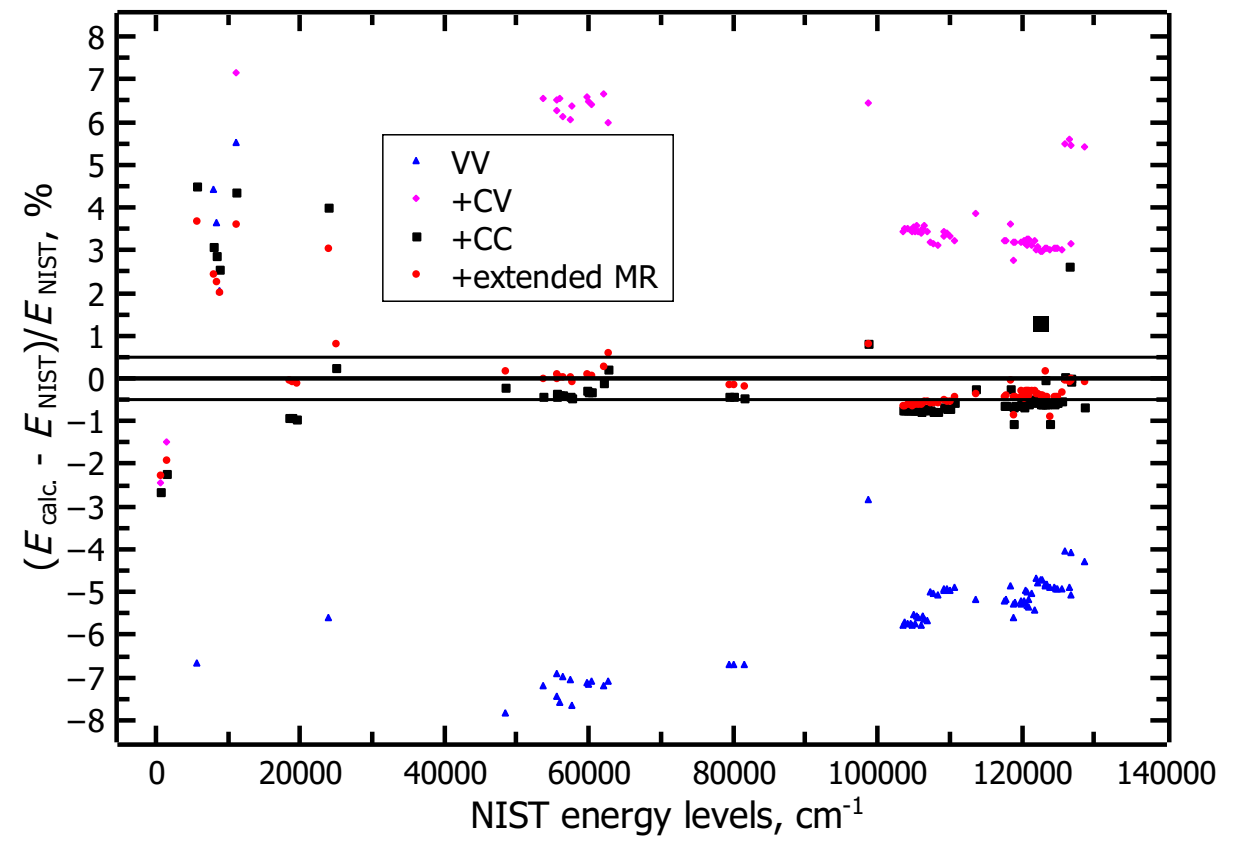

Fig. 1. Comparison of computed energy levels using different strategies with data from the NIST database. The solid lines indicate $0.5 \%$ deviation from the NIST data. configuration state functions (CSFs),

$\Psi(\gamma P J M)=\sum_{i=1}^{N_{\mathrm{CSFs}}} c_{i} \Phi\left(\gamma_{i} P J M\right)$,

where $J$ and $M$ are the angular quantum numbers and $P$ is parity. The CSFs $\Phi\left(\gamma_{i} P J M\right)$ are built from products of one-electron Dirac orbitals. In the relativistic self-consistent field procedure both the radial parts of the Dirac orbitals and the expansion coefficients were optimized to self-consistency.

In RCI computations the atomic wave function is expanded in CSFs and only the expansion coefficients are determined by diagonalizing the Hamiltonian matrix. The RCI method was used to include the transverse-photon (Breit) interaction and QED corrections: vacuum polarization and self-energy.

We obtained ASFs as expansions over $j j$-coupled CSFs. To transform these ASFs into an $L S J$-coupled CSF basis for labeling purposes, the method provided by Gaigalas et al. (Gaigalas et al. 2003, 2017) was used.

\subsection{Computational scheme}

Firstly, MCDHF calculations were performed in the extended optimal level (EOL) scheme (Dyall et al. 1989) for the weighted average of the even and odd parity states. The space of CSFs, referred to as the active space (AS), building the ASFs was obtained using the multireference-single-double (MR-SD) method (Froese Fischer et al. 2016). The MR set consists of the $4 \mathrm{~d}^{2}, 4 \mathrm{~d} 5 \mathrm{~s}, 5 \mathrm{~s}^{2}, 4 \mathrm{~d} 6 \mathrm{~s}, 4 \mathrm{~d} 5 \mathrm{~d}, 5 \mathrm{p}^{2}$ even and $4 \mathrm{~d} 5 \mathrm{p}, 5 \mathrm{~s} 5 \mathrm{p}, 4 \mathrm{~d} 6 \mathrm{p}$, $4 \mathrm{~d} 4 \mathrm{f}$ odd configurations. The orbital spaces (OS), to which single and double (SD) substitutions from the configurations in the MR were allowed, are as follows: $\mathrm{OS}_{1}=\{7 \mathrm{~s}, 7 \mathrm{p}, 6 \mathrm{~d}$, $5 \mathrm{f}\}, \ldots, \mathrm{OS}_{5}=\{11 \mathrm{~s}, 11 \mathrm{p}, 10 \mathrm{~d}, 9 \mathrm{f}, 7 \mathrm{~g}, 7 \mathrm{~h}\}$. No substitutions were allowed from the Kr-like core $\left(1 s^{2} 2 s^{2} 2 p^{6} 3 s^{2} 3 p^{6} 3 d^{10} 4 s^{2} 4\right.$ $\mathrm{p}^{6}$, further denoted as $\left.[\mathrm{Kr}]\right)$, which defines an inactive closed core. This means that only valence-valence (VV) electron correlation effects were taken into account in the MCDHF calculations. These calculations were followed by RCI calculations, including the Breit interaction and leading QED effects, that is, vacuum polarization and self-energy corrections.

Based on the orbitals from the MCDHF calculations further RCI calculations were performed. Core shells (4s and $4 p$ ) were opened for substitutions to include core electron correlation effects. To include core-valence (CV) electron correlations (VV+CV scheme), additionally single (S) substitutions from the core shells $4 \mathrm{~s}$ or $4 \mathrm{p}$ were allowed. To include core-core (CC) electron correlation effects in the RCI computations, SD substitutions were allowed from both the $4 \mathrm{~s}$ and $4 \mathrm{p}$ shells. At the last step the MR set was extended to include additional important configurations. Based on the analysis of ASFs composition, the even $4 d 6 d, 5 s 5 d$ and odd $5 \mathrm{p} 5 \mathrm{~d}$ configurations were added to the MR set. A summary of the CSFs expansions for each computational strategy is presented in Table 1. 


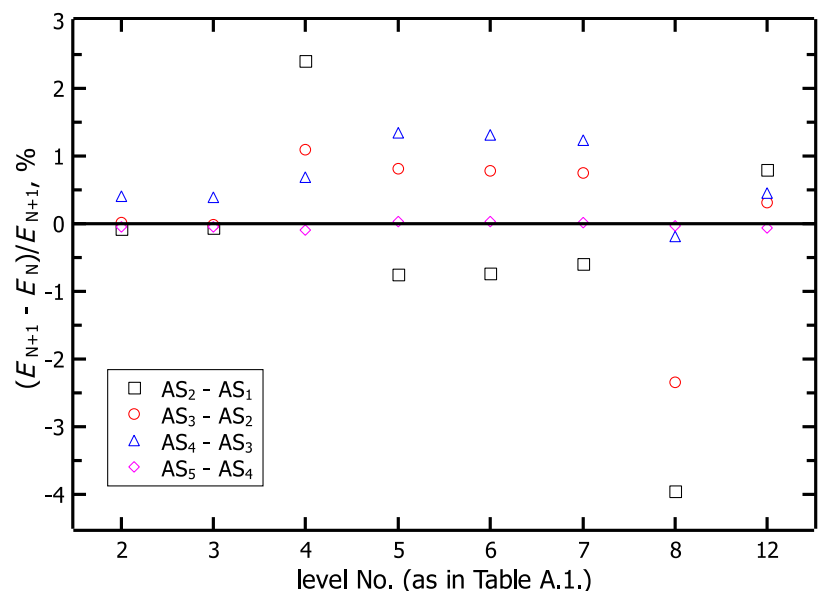

Fig. 2. Convergence of the levels of the $4 \mathrm{~d}^{2}$ configuration (VV+ $\mathrm{CV}+\mathrm{CC}+$ extended MR strategy). The number of the levels match the order of levels in Table A.1.

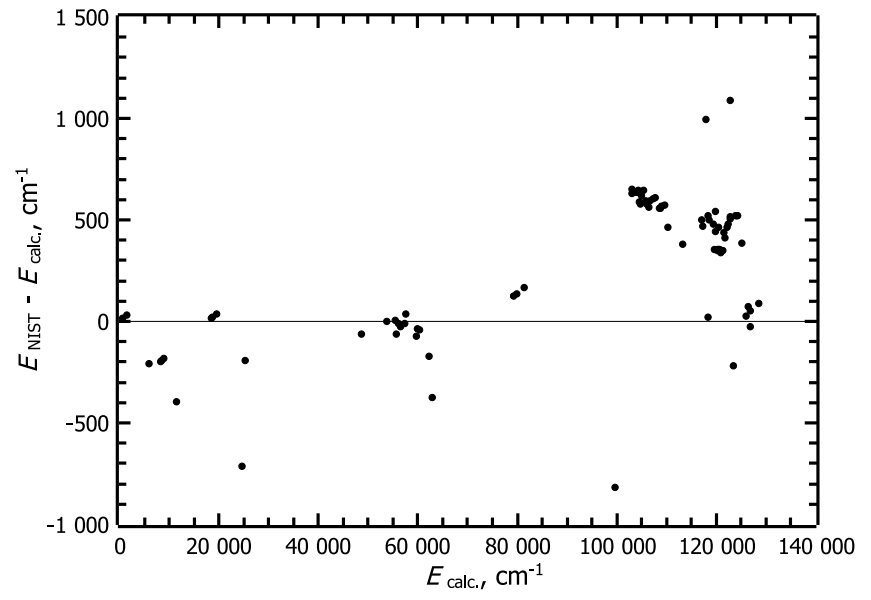

Fig. 3. Deviations of the present calculated energy levels $(\mathrm{VV}+\mathrm{CV}+$ $\mathrm{CC}+$ extended MR strategy $\mathrm{OS}_{5}$ ) from the NIST values.

The inclusion of $\mathrm{CC}$ correlations and the extension of the MR set increase the AS very rapidly. The calculations with larger ASs were thus performed with the MPI version of the GRASP2018 code.

\section{Results}

\subsection{Evaluation of energy spectra}

The influence of $\mathrm{VV}, \mathrm{CV}$, and CC electron correlation effects on the energy spectra was studied and results from these investigations are presented in Fig. 1. In the figure energy levels from different schemes based on the $\mathrm{OS}_{4}$ orbital space are compared with data from the NIST database (Kramida et al. 2019). When only VV electron correlations were taken into account, almost all energy levels are too low. The difference between computed energies and NIST recommended energy values for some levels of the ground configuration reach $18 \%$ (these points are not included in Fig. 1). The averaged difference in the VV case is about $6 \%$. The $\mathrm{CV}$ correlations increase transition energies and in the $\mathrm{VV}+\mathrm{CV}$ case the energies are too high compared with the NIST results. Figure 1 shows that the inclusion of $\mathrm{CC}$ elec-

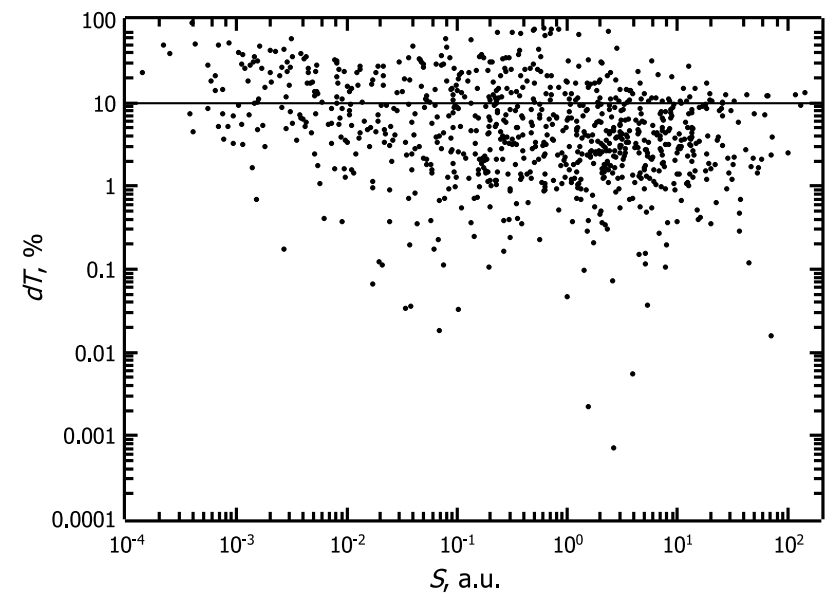

Fig. 4. Scatterplot of $d T$ vs. the line strength $S$ of E1 transitions for $\mathrm{Zr}$ III. The solid line indicates the $10 \%$ deviations.

tron correlation effects in the computations is very important. By applying the $\mathrm{VV}+\mathrm{CV}+\mathrm{CC}$ strategy, very good agreement with NIST data was achieved. The average difference of the computed energy levels relative to the energies from the NIST database is $0.84 \%$. This difference decreases and reaches $0.57 \%$ when the MR set is extended by including some additional important configurations.

As we can see from Fig. 1, the largest disagreement with NIST energy levels is for states in the ground configuration, and the difference is up to $3.68 \%$. So in Fig. 2 we represented the convergence of these states using the $\mathrm{VV}+\mathrm{CV}+\mathrm{CC}+$ extended MR strategy. Figure 2 shows that the results do not change after adding more correlations (extending $\mathrm{OS}_{4}$ to $\mathrm{OS}_{5}$ ). This means that convergence is achieved for $\mathrm{OS}_{5}$. The situation is similar for all other states and energies change by only up to $11 \mathrm{~cm}^{-1}$ when the orbital space is extended from $\mathrm{OS}_{4}$ to $\mathrm{OS}_{5}$.

The Breit and QED corrections affect the energy spectrum up to $0.8 \%$. The largest contribution, about $5 \%$, is to the $4 d^{2}{ }^{3} F_{3,4}$ states. Figure 3 presents the differences between the NIST energies and final results $(\mathrm{VV}+\mathrm{CV}+\mathrm{CC}+$ extended $\mathrm{MR}$ strategy $\mathrm{OS}_{5}$ ) of the present work. Root-mean-square (rms) deviations obtained for final energy spectra from the experimental (NIST) data are $250 \mathrm{~cm}^{-1}$ and $520 \mathrm{~cm}^{-1}$ for levels below and above $100000 \mathrm{~cm}^{-1}$, respectively.

In Table A.1 the final results obtained using the $\mathrm{VV}+\mathrm{CV}+\mathrm{CC}+$ extended MR computational scheme with $\mathrm{OS}_{5}$ are presented. The table lists energy spectra and atomic state function composition in $L S$-coupling for 40 even states of the $4 \mathrm{~d}^{2}, 4 \mathrm{~d} 5 \mathrm{~s}, 5 \mathrm{~s}^{2}, 4 \mathrm{~d} 6 \mathrm{~s}, 4 \mathrm{~d} 5 \mathrm{~d}, 5 \mathrm{p}^{2}$ configurations and for 44 odd states of the $4 d 5 p, 5 s 5 p, 4 d 6 p, 4 d 4 f$ configurations. The states are given with unique labels (Gaigalas et al. 2017). In the computed spectra there are two states (35 and 56), for which the assigned labels are not based on the largest contribution to the composition. The first state was assigned as $4 \mathrm{~d} 5 \mathrm{~d}^{3} \mathrm{D}_{3}$ with 0.35 contribution and the second state as $4 \mathrm{~d} 6 \mathrm{p}^{3} \mathrm{~F}_{2}^{\circ}$ with 0.21 contribution to the composition.

The $4 \mathrm{~d} 6 \mathrm{p}{ }^{3} \mathrm{P}_{0,1}^{\circ}$ states of the $\mathrm{Zr}$ III ion are not given in the NIST database. Our calculated excitation energies for these two states are $119058 \mathrm{~cm}^{-1}$ (for ${ }^{3} \mathrm{P}_{0}^{\circ}$ ) and $118988 \mathrm{~cm}^{-1}$ (for $\left.{ }^{3} \mathrm{P}_{1}^{\circ}\right)$. That is in good agreement with the calculated values $119613 \mathrm{~cm}^{-1}$ and $119501 \mathrm{~cm}^{-1}$ for the ${ }^{3} \mathrm{P}_{0}^{\circ}$ and ${ }^{3} \mathrm{P}_{1}^{\circ}$ states, respectively, given in Reader \& Acquista (1997). 


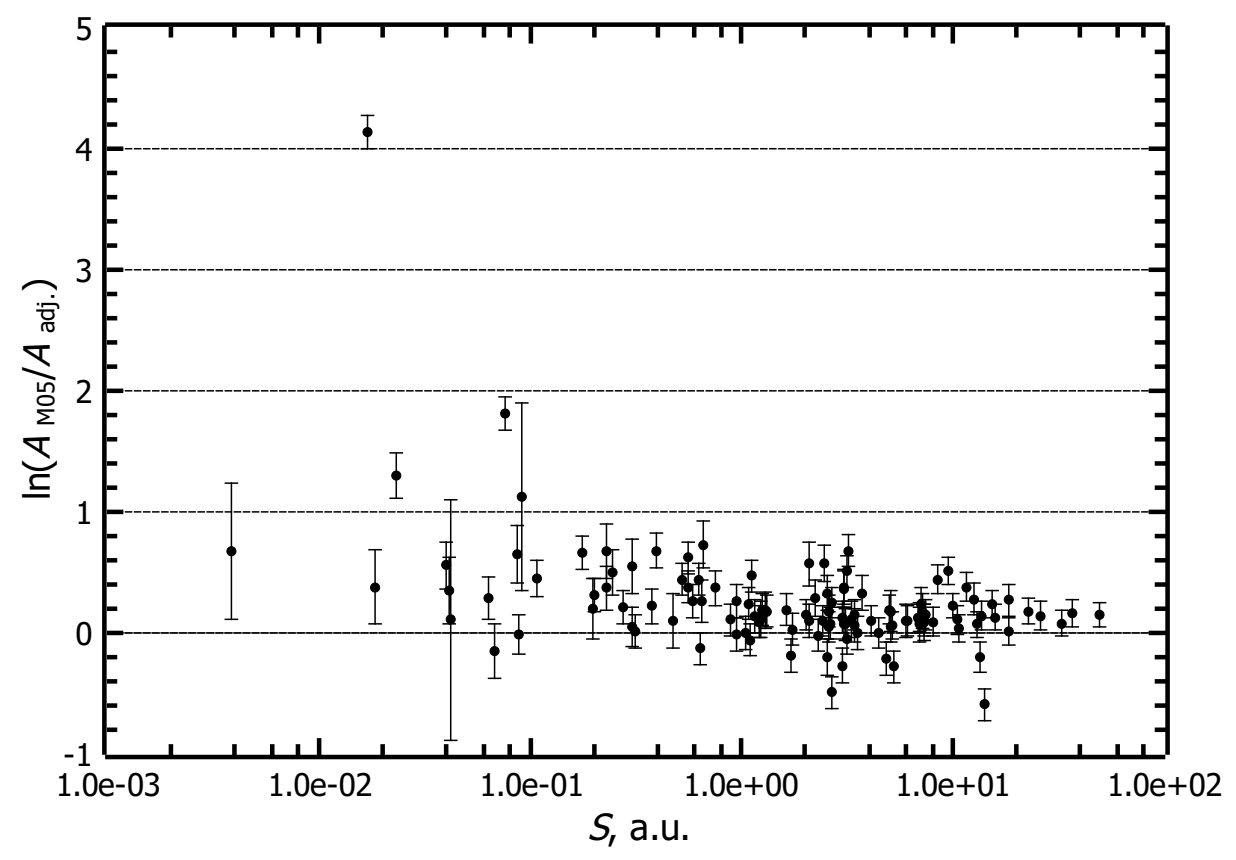

Fig. 5. Natural logarithm of the ratio of experimental $A$-values of Mayo et al. (2005) to the present adjusted (by experimental wavelengths) $A$-values plotted vs. the present calculated line strength $S$. The error bars correspond to experimental uncertainties.
Table 2. Comparison of computed lifetimes (in ns) for $\mathrm{Zr}$ III ion with experiment and other theoretical calculations.

\begin{tabular}{llcccc}
\hline \hline \multirow{2}{*}{ State } & \multirow{2}{*}{ This work } & \multirow{2}{*}{\begin{tabular}{c} 
Exp. \\
\cline { 4 - 6 }
\end{tabular}} & & \multicolumn{3}{c}{ Th. } \\
\cline { 4 - 6 } & & 1 & 1 & 2 & 3 \\
\hline $4 \mathrm{~d} 5 \mathrm{p}{ }^{1} \mathrm{D}_{2}^{o}$ & $1.86(2.45)$ & $1.76(5)$ & 1.52 & 1.53 & 1.48 \\
$4 \mathrm{~d} 5 \mathrm{p}{ }^{3} \mathrm{D}_{1}^{o}$ & $1.13(0.81)$ & $1.08(7)$ & 0.95 & 0.96 & 0.91 \\
$4 \mathrm{~d} 5 \mathrm{p}{ }^{3} \mathrm{D}_{2}^{o}$ & $1.12(0.81)$ & $1.15(4)$ & 0.92 & 0.94 & 0.89 \\
$4 \mathrm{~d} 5 \mathrm{p}{ }^{3} \mathrm{D}_{3}^{o}$ & $1.11(0.81)$ & $1.05(5)$ & 0.92 & 0.93 & 0.89 \\
$4 \mathrm{~d} 5 \mathrm{p}^{3} \mathrm{~F}_{2}^{o}$ & $1.88(2.73)$ & $1.90(10)$ & 1.55 & 1.55 & 1.51 \\
\hline
\end{tabular}

Notes. Lifetimes of present calculations are given in length form. The estimated uncertainty on the lifetime is given as a percentage in parentheses.

References. (1) Mayo et al. (2006); (2) Reader \& Acquista (1997); (3) Redfors (1991).

\subsection{Evaluation of transition data}

Transition data of electric dipole, magnetic dipole, and electric quadrupole transitions were computed using wave functions from the $\mathrm{VV}+\mathrm{CV}+\mathrm{CC}+$ extended MR strategy. The accuracy of the electric dipole (E1) and quadrupole (E2) transitions data was evaluated using the $d T$ quantity (Ekman et al. 2014), which is defined as

$d T=\frac{\left|A_{1}-A_{\mathrm{v}}\right|}{\max \left(A_{1}, A_{\mathrm{v}}\right)}$,

where $A_{1}$ and $A_{\mathrm{v}}$ are transition rates in length and velocity forms, respectively.

Obtained transition data, such as wavelengths, line strengths, weighted oscillator strengths, transition rates of E1, M1, and E2 transitions, along with the accuracy indicator $d T$, are given in Table 4. The table also gives experimental wavelengths, adjusted (by experimental wavelengths) transition rates, and uncertainty (as in the NIST database) of each transition. These uncertainties were evaluated by comparing transition rates with experimental values given by Mayo et al. (2005) and estimated using the methods described in Kramida (2013). The full table is available at the CDS.

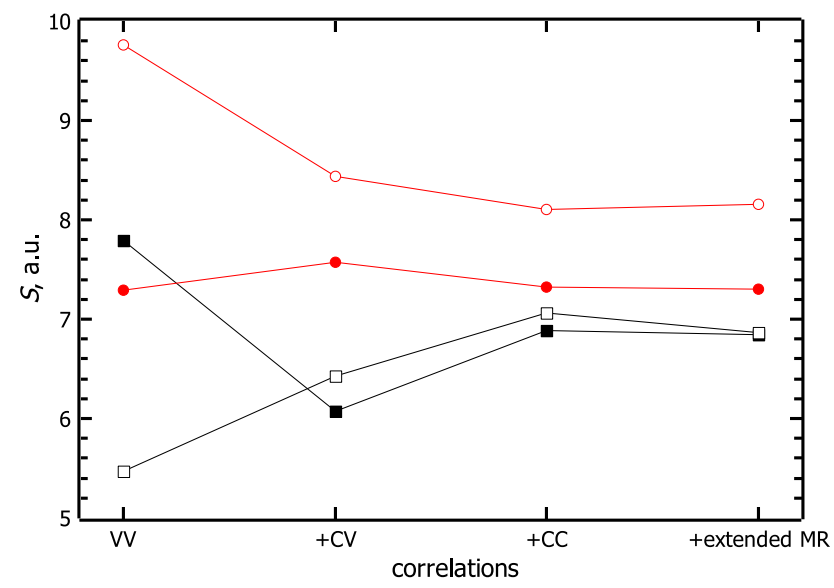

Fig. 6. Contributions of electron correlation effects to line strengths (for OS 4 ): $4 d 5 p{ }^{1} D_{2}^{o}-4 d^{2}{ }^{1} D_{2}$ (black), $4 d 5 p{ }^{1} D_{2}^{o}-4 d 5 s{ }^{1} D_{2}$ (red). Closed and open symbols indicate line strengths in length and in velocity forms, respectively.

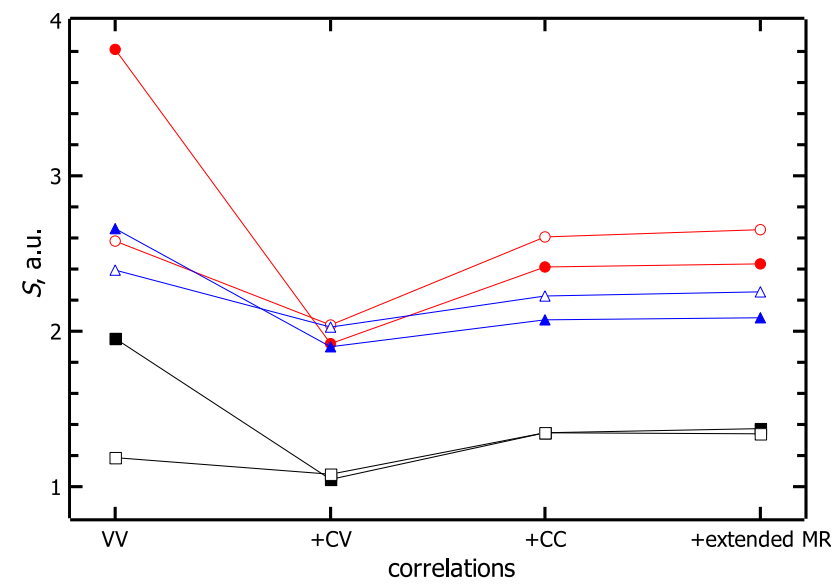

Fig. 7. Contributions of electron correlation effects to line strengths (for $\mathrm{OS}_{4}$ ): $4 \mathrm{~d} 5 \mathrm{p}{ }^{1} \mathrm{D}_{2}^{o}-4 \mathrm{~d}^{2}{ }^{3} \mathrm{~F}_{2}$ (black), $4 \mathrm{~d} 5 \mathrm{p}{ }^{1} \mathrm{D}_{2}^{o}-4 \mathrm{~d} 5 \mathrm{~s}{ }^{3} \mathrm{D}_{1}$ (red), and $4 \mathrm{~d} 5 \mathrm{p}{ }^{1} \mathrm{D}_{2}^{o}-4 \mathrm{~d} 5 \mathrm{~s}{ }^{3} \mathrm{D}_{2}$ (blue). Closed and open symbols indicate line strengths in length and in velocity forms, respectively. 
Table 3. Comparison of computed line strengths (in atomic units) for $\mathrm{Zr}$ III ion with experiment and other theoretical calculations.

\begin{tabular}{|c|c|c|c|c|c|c|c|c|c|}
\hline \multirow[t]{2}{*}{ Upper state } & \multirow[t]{2}{*}{ Lower state } & \multicolumn{4}{|c|}{ This work } & \multirow{2}{*}{$\begin{array}{c}\text { Exp. } \\
1\end{array}$} & \multicolumn{3}{|c|}{ Th. } \\
\hline & & $\mathrm{VV}$ & $+\mathrm{CV}$ & $+\mathrm{CC}$ & +extended MR & & 1 & 2 & 3 \\
\hline $4 \mathrm{~d} 5 \mathrm{p}^{1} \mathrm{D}_{2}^{o}$ & $4 d^{2}{ }^{3} F_{2}$ & 1.95 & 1.04 & 1.34 & 1.37 & & & 1.93 & 1.69 \\
\hline $4 \mathrm{~d} 5 \mathrm{p}^{1} \mathrm{D}_{2}^{o}$ & $4 d^{2}{ }^{1} D_{2}$ & 7.79 & 6.07 & 6.88 & 6.84 & 7.31 & 7.65 & 7.52 & 8.85 \\
\hline $4 \mathrm{~d} 5 \mathrm{p}^{1} \mathrm{D}_{2}^{o}$ & $4 d 5 s^{3} D_{1}$ & 3.81 & 1.92 & 2.41 & 2.44 & 4.09 & 3.52 & 3.69 & 3.16 \\
\hline $4 \mathrm{~d} 5 \mathrm{p}^{1} \mathrm{D}_{2}^{\mathrm{o}}$ & $4 d 5 s{ }^{3} D_{2}$ & 2.66 & 1.90 & 2.08 & 2.09 & 3.49 & 3.12 & 3.06 & 2.66 \\
\hline $4 \mathrm{~d} 5 \mathrm{p}^{1} \mathrm{D}_{2}^{o}$ & $4 \mathrm{~d} 5 \mathrm{~s}{ }^{1} \mathrm{D}_{2}$ & 7.29 & 7.58 & 7.32 & 7.30 & 7.56 & 8.55 & 7.86 & 7.60 \\
\hline
\end{tabular}

Notes. Line strengths of present calculations are given in length form.

References. (1) Mayo et al. (2005); (2) Reader \& Acquista (1997); (3) Redfors (1991).

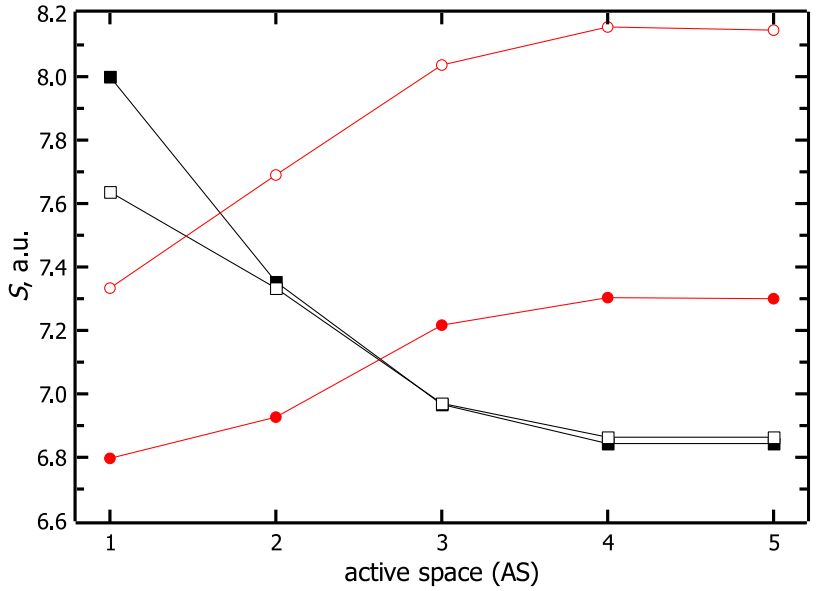

Fig. 8. Convergence of line strengths using the $\mathrm{VV}+\mathrm{CV}+\mathrm{CC}+$ extended MR strategy; $4 \mathrm{~d} 5 \mathrm{p}{ }^{1} \mathrm{D}_{2}^{o}-4 \mathrm{~d}^{2}{ }^{1} \mathrm{D}_{2}$ (black), $4 \mathrm{~d} 5 \mathrm{p}{ }^{1} \mathrm{D}_{2}^{o}-4 \mathrm{~d} 5 \mathrm{~s}{ }^{1} \mathrm{D}_{2}$ (red). Closed and open symbols denote line strengths in length and in velocity forms, respectively.

A scatterplot of $d T$ versus the line strengths is presented in Fig. 4 to show the difference between length and velocity forms of computed E1 transitions. As we can see from the figure for most of the stronger transitions, $d T$ is well below $10 \%$.

In Fig. 5 transition rates from experiment (Mayo et al. 2005) are compared with results from this work. As shown in the figure, most of the computed transition rates are smaller than experimental rates. The differences for weaker transitions are much larger than the experimental error bars. The worst disagreement is for four transitions, namely $4 \mathrm{~d} 5 \mathrm{~d}^{3} \mathrm{D}_{3}$ (No. 35) $-4 \mathrm{~d} 5 \mathrm{p}{ }^{3} \mathrm{D}_{2}^{o}$ (No. 19); 4d5d ${ }^{3} \mathrm{D}_{3}$ (No. 35) - 4d5p ${ }^{3} \mathrm{~F}_{4}^{o}$ (No. 21); $4 \mathrm{~d} 5 \mathrm{p}^{3} \mathrm{D}_{2}^{o}$ (No. 19) - 4d5s ${ }^{1} \mathrm{D}_{2}$ (No. 13); $4 \mathrm{~d} 5 \mathrm{p}{ }^{3} \mathrm{D}_{1}^{o}$ (No. 17) - 4d5s ${ }^{1} \mathrm{D}_{2}$ (No. 13).

Lifetimes for the studied levels were computed in length and velocity gauges and the results are presented in Table A.1. Computed lifetimes for some states of the $4 \mathrm{~d} 5 \mathrm{p}$ configuration are compared with experimental values and other theoretical calculations in Table 2. From this table we can see that the lifetimes obtained in this work agree with the experimental lifetimes within the uncertainties of the latter. Other theoretical lifetimes are lower than the experimental lifetimes by (11-22)\%.

We chose five E1 transitions, which contribute significantly to the lifetime of $4 \mathrm{~d} 5 \mathrm{p}^{1} \mathrm{D}_{2}^{o}$ state, for a deeper analysis. The influence of electron correlations to the line strengths of these five lines is presented in Figs. 6 and 7. As shown in both figures, it is important to include $\mathrm{CV}$ and $\mathrm{CC}$ correlations in the computations. The line strengths for $4 \mathrm{~d} 5 \mathrm{p}{ }^{1} \mathrm{D}_{2}^{o}-4 \mathrm{~d}^{2}{ }^{3} \mathrm{~F}_{2}, 4 \mathrm{~d} 5 \mathrm{p}{ }^{1} \mathrm{D}_{2}^{o}-$

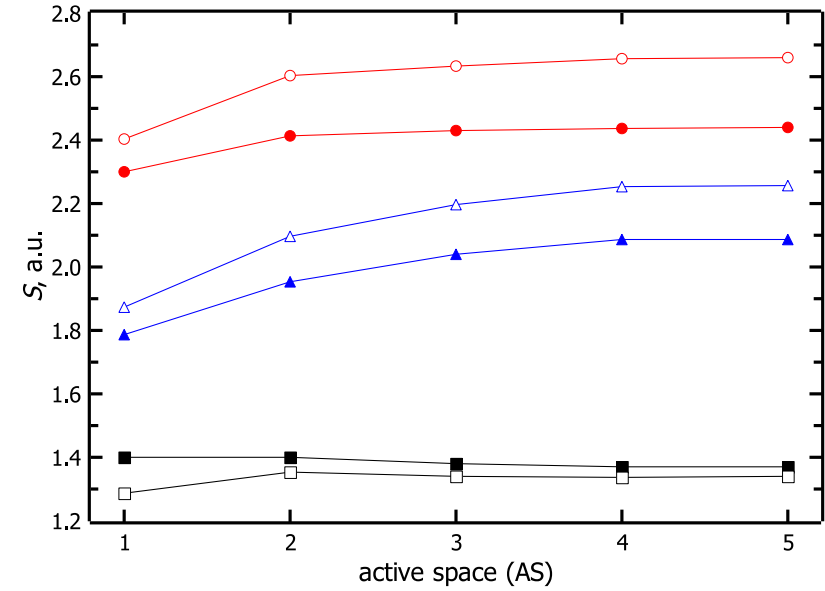

Fig. 9. Convergence of line strengths using the $\mathrm{VV}+\mathrm{CV}+\mathrm{CC}+$ extended MR strategy; 4d5p ${ }^{1} \mathrm{D}_{2}^{o}-4 \mathrm{~d}^{2}{ }^{3} \mathrm{~F}_{2}$ (black), $4 \mathrm{~d} 5 \mathrm{p}{ }^{1} \mathrm{D}_{2}^{o}-4 \mathrm{~d} 5 \mathrm{~s}{ }^{3} \mathrm{D}_{1}$ (red), $4 \mathrm{~d} 5 \mathrm{p}{ }^{1} \mathrm{D}_{2}^{o}-4 \mathrm{~d} 5 \mathrm{~s}^{3} \mathrm{D}_{2}$ (blue). Closed and open symbols indicate line strengths in length and in velocity forms, respectively.

$4 \mathrm{~d} 5 \mathrm{~s}{ }^{3} \mathrm{D}_{1}$ transitions (Fig. 7) decreases by 1.5 times when $\mathrm{CV}$ and $\mathrm{CC}$ correlations are included. In Table 3 , as an example, line strengths of these five lines are also compared with experimental results and other theoretical computations. Computed line strengths using the $\mathrm{VV}+\mathrm{CV}+\mathrm{CC}+$ extended MR strategy disagree with experimental and other theoretical results. A better agreement with other investigations is achieved when only VV correlations are included.

In Figs. 8 and 9 convergence of line strengths in length and velocity forms using the $\mathrm{VV}+\mathrm{CV}+\mathrm{CC}+$ extended MR strategy is shown. We see that convergence of line strengths in both forms is achieved. The $d T$ for the $4 \mathrm{~d} 5 \mathrm{p}{ }^{1} \mathrm{D}_{2}^{o}-4 \mathrm{~d}^{2}{ }^{1} \mathrm{D}_{2}$ transition is $0.3 \%$ and for $4 \mathrm{~d} 5 \mathrm{p}^{1} \mathrm{D}_{2}^{o}-4 \mathrm{~d} 5 \mathrm{~s}{ }^{1} \mathrm{D}_{2}$ transition $-10.4 \%$ (Fig. 8); the $d T$ values for $4 \mathrm{~d} 5 \mathrm{p}{ }^{1} \mathrm{D}_{2}^{o}-4 \mathrm{~d}^{2}{ }^{3} \mathrm{~F}_{2}, 4 \mathrm{~d} 5 \mathrm{p}{ }^{1} \mathrm{D}_{2}^{o}-4 \mathrm{~d} 5 \mathrm{~s}{ }^{3} \mathrm{D}_{1}$, $4 \mathrm{~d} 5 \mathrm{p}{ }^{1} \mathrm{D}_{2}^{o}-4 \mathrm{~d} 5 \mathrm{~s}{ }^{3} \mathrm{D}_{2}$ transitions are $2.4 \%, 8.3 \%$, and $7.5 \%$, respectively (Fig. 9).

\section{Conclusions}

Energy spectra and transition data of E1, M1, and E2 transitions are presented for $\mathrm{Zr}$ III using MCDHF and RCI methods.

Various electron correlation effects were studied. The CV and CC electron correlations are very important in the energy spectra investigations for $\mathrm{Zr}$ III ion. The analysis shows that the line strengths for computed transitions are sensitive to $\mathrm{CV}$ and $\mathrm{CC}$ correlations as well. 
The rms deviations obtained for final energy spectra (VV+ $\mathrm{CV}+\mathrm{CC}+$ extended $\mathrm{MR}$ strategy $\mathrm{OS}_{5}$ ) from the experimental data are $250 \mathrm{~cm}^{-1}$ and $520 \mathrm{~cm}^{-1}$ for levels below and above $100000 \mathrm{~cm}^{-1}$, respectively.

The computed lifetimes agree with available experimental values within the uncertainties of the latter. The accuracy of the transition rates has been evaluated. About $7 \%$ of all E1 transitions have uncertainties of $18 \%$ in $A$ values (NIST category $\mathrm{C}+$ ), $41 \%$ have uncertainties of $29 \%$ (NIST category D+), $24 \%$ have uncertainties of $54 \%$ (NIST category D), and only $28 \%$ have greater uncertainties corresponding to NIST category E. These estimates should be redone when more experimental data appear considering the reasons given below.

It was observed that there are some disagreements between results of both Mayo papers (Mayo et al. 2006, 2005). By comparing computed lifetimes with measured values from Mayo et al. (2006) they agree within the uncertainties of the experiment. However, when the computed transition rates are compared with the rates presented in Mayo et al. (2005) there is a large disagreement. The disagreement could appear due to the fact that transition probabilities in Mayo et al. (2005) were obtained from the branching ratio measurements and the theoretical lifetime values were calculated in their work but not obtained from experimental measurements. It is impossible to carry out a deeper analysis because these authors did not present the lifetimes to which they normalized their measured branching fractions and did not give $A$ values for the unobserved decay branches. Further studies and measurements are needed to explain these disagreements.

Acknowledgements. This project has received funding from European Social Fund (project No. 09.3.3-LMT-K-712-02-0072) under grant agreement with the Research Council of Lithuania (LMTLT). Part of large-scale computations were performed at the High Performance Computing Center "HPC Sauletekis" of the Faculty of Physics at Vilnius University.

\section{References}

Beck, D. R., \& Pan, L. 2004, Phys. Scr., 69, 91

Castelli, F., Cowley, C. R., Ayres, T. R., Catanzaro, G., \& Leone, F. 2017, A\&A, 601, A119

Charro, E., López-Ayuso, J. L., \& Martín, I. 1999, J. Phys. B: At. Mol. Opt. Phys., 32, 4555

Dyall, K., Grant, I., Johnson, C., Parpia, F., \& Plummer, E. 1989, Comput. Phys. Commun., 55, 425

Ekman, J., Godefroid, M., \& Hartman, H. 2014, Atoms, 2, 215

Froese Fischer, C., Godefroid, M., Brage, T., Jönsson, P., \& Gaigalas, G. 2016, J. Phys. B: At. Mol. Opt. Phys., 49, 182004

Froese Fischer, C., Gaigalas, G., Jönsson, P., \& Bieroń, J. 2019, Comput. Phys. Commun., 237, 184

Gaigalas, G., Žalandauskas, T., \& Rudzikas, Z. 2003, At. Data Nucl. Data Tables, 84,99

Gaigalas, G., Froese Fischer, C., Rynkun, P., \& Jönsson, P. 2017, Atoms, 5, 6

Grant, I. P. 2007, Relativistic Quantum Theory of Atoms and Molecules (New York: Springer)

Kramida, A. 2013, Fusion Sci. Technol., 63, 313

Kramida, A., Ralchenko, Yu, Reader, J., \& NIST ASD Team 2019, NIST Atomic Spectra Database (ver. 5.7.1), [Online] (Gaithersburg, MD: National Institute of Standards and Technology), Available: https://physics.nist.gov/ asd [2019, November 14]

Leckrone, D. S., Johansson, S., Wahlgren, G. M., \& Adelman, S. J. 1993, Phys. Scr., T47, 149

Martins, M. C., Santos, J. P., Costa, A. M., \& Parente, F. 2006, Eur. Phys. J. D At. Mol. Opt. Plasma Phys., 39, 167

Mayo, R., Ortiz, M., \& Campos, J. 2005, J. Quant. Spectr. Radiat. Trans., 94, 109

Mayo, R., Campos, J., Ortiz, M., et al. 2006, Eur. Phys. J. D, 40, 169

Pandey, G., Lambert, D. L., Rao, N. K., \& Jeffery, C. S. 2004, ApJ, 602, L113

Reader, J., \& Acquista, N. 1997, Phys. Scr., 55, 310

Redfors, A. 1991, A\&A, 249, 589

Sikström, C. M., Lundberg, H., Wahlgren, G. M., et al. 1999, A\&A, 343, 297 


\section{Appendix A: Atomic state function composition in LS-coupling, energy levels, and lifetimes for the Zr III ion.}

Table A.1. Atomic state function composition (up to three $L S$ components with a contribution $>0.02$ of the total wave function) in $L S$-coupling, energy levels (in $\mathrm{cm}^{-1}$ ), and lifetimes (in s; given in length $\left(\tau_{l}\right)$ and velocity $\left(\tau_{v}\right)$ gauges) for $\mathrm{Zr}$ III.

\begin{tabular}{|c|c|c|c|c|c|c|}
\hline No. & State & $L S$-composition & $E_{\mathrm{RCI}}$ & $E_{\mathrm{NIST}}$ & $\tau_{l}$ & $\tau_{v}$ \\
\hline 1 & $4 d^{2}\left({ }_{2}^{3} F\right){ }^{3} F_{2}$ & 0.92 & 0 & 0 & & \\
\hline 2 & $4 d^{2}\left({ }_{2}^{3} F\right){ }^{3} F_{3}$ & 0.93 & 666 & 682 & $1.33 \mathrm{e}+02$ & $1.33 \mathrm{e}+02$ \\
\hline 3 & $4 d^{2}\left({ }_{2}^{3} F\right){ }^{3} F_{4}$ & 0.93 & 1457 & 1486 & $9.98 \mathrm{e}+01$ & $9.98 \mathrm{e}+01$ \\
\hline 4 & $4 d^{2}\left({ }_{2}^{1} D\right){ }^{1} D_{2}$ & $0.82+0.064 \mathrm{~d} 5 \mathrm{~s}^{1} \mathrm{D}+0.034 \mathrm{~d}^{2}\left({ }_{2}^{3} \mathrm{P}\right){ }^{3} \mathrm{P}$ & 5949 & 5743 & $1.12 \mathrm{e}+01$ & $1.12 \mathrm{e}+01$ \\
\hline 5 & $4 \mathrm{~d}^{2}\left({ }_{2}^{3} \mathrm{P}\right){ }^{3} \mathrm{P}_{0}$ & 0.92 & 8262 & 8064 & $2.64 \mathrm{e}+01$ & $2.95 \mathrm{e}+01$ \\
\hline 6 & $4 \mathrm{~d}^{2}\left({ }_{2}^{3} \mathrm{P}\right){ }^{3} \mathrm{P}_{1}$ & 0.92 & 8518 & 8327 & $2.12 \mathrm{e}+01$ & $2.29 \mathrm{e}+01$ \\
\hline 7 & $4 d^{2}\left({ }_{2}^{3} \mathrm{P}\right){ }^{3} \mathrm{P}_{2}$ & $0.89+0.034 \mathrm{~d}^{2}\left({ }_{2}^{1} \mathrm{D}\right){ }^{1} \mathrm{D}$ & 9021 & 8840 & $1.43 \mathrm{e}+01$ & $1.49 \mathrm{e}+01$ \\
\hline 8 & $4 d^{2}\left({ }_{2}^{1} G\right){ }^{1} G_{4}$ & 0.92 & 11447 & 11051 & $1.05 \mathrm{e}+01$ & $1.05 \mathrm{e}+01$ \\
\hline 9 & $4 \mathrm{~d} 5 \mathrm{~s}{ }^{3} \mathrm{D}_{1}$ & 0.94 & 18383 & 18401 & $2.42 \mathrm{e}-01$ & $2.63 e-01$ \\
\hline 10 & $4 d 5 s{ }^{3} \mathrm{D}_{2}$ & 0.93 & 18784 & 18805 & $2.39 \mathrm{e}-01$ & $2.61 \mathrm{e}-01$ \\
\hline 11 & $4 d 5 s^{3} \mathrm{D}_{3}$ & 0.94 & 19502 & 19536 & $2.33 \mathrm{e}-01$ & $2.53 \mathrm{e}-01$ \\
\hline 12 & $4 d^{2}\left({ }_{0}^{1} S\right){ }^{1} S_{0}$ & $0.83+0.065 \mathrm{~s}^{2}{ }^{1} \mathrm{~S}+0.034 \mathrm{~d} 5 \mathrm{~d}{ }^{1} \mathrm{~S}$ & 24694 & 23979 & $1.94 \mathrm{e}-01$ & $2.13 \mathrm{e}-01$ \\
\hline 13 & $4 \mathrm{~d} 5 \mathrm{~s}{ }^{1} \mathrm{D}_{2}$ & $0.86+0.064 \mathrm{~d}^{2}\left({ }_{2}^{1} \mathrm{D}\right){ }^{1} \mathrm{D}$ & 25261 & 25068 & $2.82 \mathrm{e}-01$ & $3.06 \mathrm{e}-01$ \\
\hline 14 & $5 s^{2}{ }^{1} S_{0}$ & $0.84+0.064 \mathrm{~d}^{2}\left({ }_{0}^{1} \mathrm{~S}\right){ }^{1} \mathrm{~S}+0.045 \mathrm{p}^{2}\left({ }_{0}^{1} \mathrm{~S}\right){ }^{1} \mathrm{~S}$ & 48570 & 48507 & $1.63 \mathrm{e}-02$ & $1.65 \mathrm{e}-02$ \\
\hline 15 & $4 \mathrm{~d} 5 \mathrm{p}^{1} \mathrm{D}_{2}^{\circ}$ & $0.68+0.244 \mathrm{~d} 5 \mathrm{p}^{3} \mathrm{~F}^{\circ}$ & 53651 & 53649 & $1.86 \mathrm{e}-09$ & $1.82 \mathrm{e}-09$ \\
\hline 16 & $4 \mathrm{~d} 5 \mathrm{p}^{3} \mathrm{~F}_{2}^{\circ}$ & $0.65+0.254 \mathrm{~d} 5 \mathrm{p}^{1} \mathrm{D}^{\circ}+0.034 \mathrm{~d} 5 \mathrm{p}^{3} \mathrm{D}^{\circ}$ & 55553 & 55558 & $1.88 \mathrm{e}-09$ & $1.83 \mathrm{e}-09$ \\
\hline 17 & $4 d 5 p^{3} \mathrm{D}_{1}^{\circ}$ & $0.90+0.024 \mathrm{~d} 5 \mathrm{p}^{1} \mathrm{P}^{\circ}$ & 55676 & 55616 & $1.13 \mathrm{e}-09$ & $1.12 \mathrm{e}-09$ \\
\hline 18 & $4 \mathrm{~d} 5 \mathrm{p}^{3} \mathrm{~F}_{3}^{\circ}$ & $0.86+0.084 \mathrm{~d} 5 \mathrm{p}^{3} \mathrm{D}^{\circ}$ & 56087 & 56077 & $1.88 \mathrm{e}-09$ & $1.83 \mathrm{e}-09$ \\
\hline 19 & $4 d 5 p^{3} D_{2}^{3}$ & $0.88+0.054 \mathrm{~d} 5 \mathrm{p}^{3} \mathrm{~F}^{\circ}$ & 56465 & 56438 & $1.12 \mathrm{e}-09$ & $1.11 \mathrm{e}-09$ \\
\hline 20 & $4 d 5 p^{3} \mathrm{D}_{3}^{\circ}$ & $0.85+0.084 \mathrm{~d} 5 \mathrm{p}^{3} \mathrm{~F}^{\circ}$ & 57359 & 57349 & $1.11 \mathrm{e}-09$ & $1.10 \mathrm{e}-09$ \\
\hline 21 & $4 d 5 p^{3} F_{4}^{\circ}$ & 0.94 & 57649 & 57684 & $1.88 \mathrm{e}-09$ & $1.82 \mathrm{e}-09$ \\
\hline 22 & $4 d 5 p^{3} \mathrm{P}_{1}^{\circ}$ & $0.78+0.114 \mathrm{~d} 5 \mathrm{p}^{1} \mathrm{P}^{\circ}+0.024 \mathrm{~d} 5 \mathrm{p}^{3} \mathrm{D}^{\circ}$ & 59771 & 59699 & $1.54 \mathrm{e}-09$ & $1.52 \mathrm{e}-09$ \\
\hline 23 & $4 d 5 \mathrm{p}^{3} \mathrm{P}_{0}^{\circ}$ & 0.92 & 59985 & 59948 & $1.48 \mathrm{e}-09$ & $1.46 \mathrm{e}-09$ \\
\hline 24 & $4 d 5 p^{3} \mathrm{P}_{2}^{\circ}$ & 0.90 & 60401 & 60358 & $1.47 \mathrm{e}-09$ & $1.45 \mathrm{e}-09$ \\
\hline 25 & $4 \mathrm{~d} 5 \mathrm{p}^{1} \mathrm{P}_{1}^{2}$ & $0.74+0.134 \mathrm{~d} 5 \mathrm{p}^{3} \mathrm{P}^{\circ}+0.065 \mathrm{~s} 5 \mathrm{p}^{1} \mathrm{P}^{\circ}$ & 62288 & 62117 & $1.94 \mathrm{e}-09$ & $1.92 \mathrm{e}-09$ \\
\hline 26 & $4 \mathrm{~d} 5 \mathrm{p}^{1} \mathrm{~F}_{3}^{\circ}$ & 0.91 & 62967 & 62591 & $1.07 \mathrm{e}-09$ & $1.06 \mathrm{e}-09$ \\
\hline 27 & $5 \mathrm{~s} 5 \mathrm{p}^{3} \mathrm{P}_{0}^{\circ}$ & 0.92 & 79317 & 79440 & $1.22 \mathrm{e}-09$ & $1.22 \mathrm{e}-09$ \\
\hline 28 & $5 \mathrm{~s} 5 \mathrm{p}^{3} \mathrm{P}_{1}^{\circ}$ & 0.92 & 79974 & 80107 & $1.22 \mathrm{e}-09$ & $1.22 \mathrm{e}-09$ \\
\hline 29 & $5 \mathrm{~s} 5 \mathrm{p}^{3} \mathrm{P}_{2}^{\circ}$ & 0.92 & 81389 & 81558 & $1.22 \mathrm{e}-09$ & $1.23 \mathrm{e}-09$ \\
\hline 30 & $5 \mathrm{~s} 5 \mathrm{p}^{1} \mathrm{P}_{1}^{\circ}$ & $0.80+0.054 \mathrm{~d} 5 \mathrm{p}{ }^{1} \mathrm{P}^{\circ}+0.034 \mathrm{~d} 4 \mathrm{f}^{1} \mathrm{P}^{\circ}$ & 99580 & 98763 & $3.77 \mathrm{e}-10$ & $3.79 \mathrm{e}-10$ \\
\hline 31 & $4 d 5 d^{1} F_{3}$ & $0.78+0.094 \mathrm{~d} 5 \mathrm{~d}^{3} \mathrm{D}+0.064 \mathrm{~d} 5 \mathrm{~d}^{3} \mathrm{G}$ & 102932 & 103585 & $1.03 \mathrm{e}-09$ & $1.06 \mathrm{e}-09$ \\
\hline 32 & $4 d 5 d^{3} D_{1}$ & $0.70+0.164 d 6 \mathrm{~s}^{3} \mathrm{D}+0.074 \mathrm{~d} 5 \mathrm{~d}^{1} \mathrm{P}$ & 103093 & 103725 & $1.02 \mathrm{e}-09$ & $1.06 \mathrm{e}-09$ \\
\hline 33 & $4 d 5 d^{3} D_{2}$ & $0.72+0.194 \mathrm{~d} 6 \mathrm{~s}^{3} \mathrm{D}$ & 103477 & 104111 & $1.04 \mathrm{e}-09$ & $1.07 \mathrm{e}-09$ \\
\hline 34 & $4 d 5 d^{3} G_{3}$ & $0.51+0.374 \mathrm{~d} 5 \mathrm{~d}^{3} \mathrm{D}+0.064 \mathrm{~d} 6 \mathrm{~s}^{3} \mathrm{D}$ & 104001 & 104637 & $1.01 \mathrm{e}-09$ & $1.04 \mathrm{e}-09$ \\
\hline 35 & $4 d 5 d^{3} D_{3}$ & $\mathbf{0 . 3 5}+0.374 \mathrm{~d} 5 \mathrm{~d}^{3} \mathrm{G}+0.154 \mathrm{~d} 5 \mathrm{~d}^{1} \mathrm{~F}$ & 104237 & 104883 & $1.03 \mathrm{e}-09$ & $1.06 \mathrm{e}-09$ \\
\hline 36 & $4 d 6 s^{3} \mathrm{D}_{1}$ & $0.65+0.234 \mathrm{~d} 5 \mathrm{~d}^{1} \mathrm{P}+0.054 \mathrm{~d} 5 \mathrm{~d}^{3} \mathrm{D}$ & 104426 & 105012 & $1.12 \mathrm{e}-09$ & $1.15 \mathrm{e}-09$ \\
\hline 37 & $4 d 5 d^{3} G_{4}$ & 0.93 & 104559 & 105193 & $1.00 \mathrm{e}-09$ & $1.03 \mathrm{e}-09$ \\
\hline 38 & $4 d 6 s{ }^{3} \mathrm{D}_{2}$ & $0.54+0.204 \mathrm{~d} 5 \mathrm{~d}^{3} \mathrm{D}+0.194 \mathrm{~d} 6 \mathrm{~s}^{1} \mathrm{D}$ & 104747 & 105326 & $1.13 \mathrm{e}-09$ & $1.15 \mathrm{e}-09$ \\
\hline 39 & $4 d 5 d{ }^{1} P_{1}$ & $0.57+0.184 \mathrm{~d} 5 \mathrm{~d}^{3} \mathrm{D}+0.134 \mathrm{~d} 6 \mathrm{~s}^{3} \mathrm{D}$ & 104935 & 105555 & $1.12 \mathrm{e}-09$ & $1.16 \mathrm{e}-09$ \\
\hline 40 & $4 d 5 d^{3} G_{5}$ & 0.94 & 105325 & 105970 & $1.02 \mathrm{e}-09$ & $1.04 \mathrm{e}-09$ \\
\hline 41 & $4 d 6 s{ }^{3} \mathrm{D}_{3}$ & $0.80+0.134 \mathrm{~d} 5 \mathrm{~d}^{3} \mathrm{D}$ & 105714 & 106306 & $1.13 \mathrm{e}-09$ & $1.16 \mathrm{e}-09$ \\
\hline 42 & $4 \mathrm{~d} 6 \mathrm{~s}{ }^{1} \mathrm{D}_{2}$ & $0.64+0.204 d 6 \mathrm{~s}^{3} \mathrm{D}+0.074 \mathrm{~d} 5 \mathrm{~d}^{1} \mathrm{D}$ & 105928 & 106504 & $1.09 \mathrm{e}-09$ & $1.11 \mathrm{e}-09$ \\
\hline 43 & $4 d 5 d^{3} S_{1}$ & $0.85+0.074 \mathrm{~d} 5 \mathrm{~d}^{1} \mathrm{P}$ & 106423 & 106986 & $1.07 \mathrm{e}-09$ & $1.11 \mathrm{e}-09$ \\
\hline 44 & $4 d 5 d^{3} F_{2}$ & $0.88+0.034 \mathrm{~d} 6 \mathrm{~s}^{1} \mathrm{D}+0.024 \mathrm{~d} 5 \mathrm{~d}^{1} \mathrm{D}$ & 106664 & 107257 & $9.39 \mathrm{e}-10$ & $9.52 \mathrm{e}-10$ \\
\hline 45 & $4 d 5 d^{3} F_{3}$ & 0.92 & 107219 & 107824 & $9.35 \mathrm{e}-10$ & $9.49 \mathrm{e}-10$ \\
\hline 46 & $4 d 5 d^{3} F_{4}$ & 0.92 & 107711 & 108319 & $9.52 \mathrm{e}-10$ & $9.66 \mathrm{e}-10$ \\
\hline
\end{tabular}

Notes. Energy levels are given relative to the ground state. The states 35 and 56 are indicated in bold. The labels for these levels were not assigned by the largest contribution to the composition. 
Table A.1. continued.

\begin{tabular}{|c|c|c|c|c|c|c|}
\hline No. & State & $L S$-composition & $E_{\mathrm{RCI}}$ & $E_{\mathrm{NIST}}$ & $\tau_{l}$ & $\tau_{v}$ \\
\hline 47 & $4 d 5 d^{3} P_{0}$ & $0.87+0.045 \mathrm{p}^{2}\left({ }_{2}^{3} \mathrm{P}\right){ }^{3} \mathrm{P}+0.024 \mathrm{~d} 5 \mathrm{~d}^{1} \mathrm{~S}$ & 108657 & 109212 & $1.43 \mathrm{e}-09$ & $1.41 \mathrm{e}-09$ \\
\hline 48 & $4 \mathrm{~d} 5 \mathrm{~d}{ }^{1} \mathrm{D}_{2}$ & $0.57+0.264 \mathrm{~d} 5 \mathrm{~d}^{3} \mathrm{P}+0.054 \mathrm{~d} 6 \mathrm{~s}{ }^{1} \mathrm{D}$ & 108718 & 109273 & $1.19 \mathrm{e}-09$ & $1.18 \mathrm{e}-09$ \\
\hline 49 & $4 d 5 d^{3} P_{1}$ & $0.87+0.045 \mathrm{p}^{2}\left({ }_{2}^{3} \mathrm{P}\right){ }^{3} \mathrm{P}+0.024 \mathrm{~d} 5 \mathrm{~d}^{3} \mathrm{~S}$ & 109034 & 109603 & $1.39 \mathrm{e}-09$ & $1.37 \mathrm{e}-09$ \\
\hline 50 & $4 d 5 d^{3} P_{2}$ & $0.63+0.254 \mathrm{~d} 5 \mathrm{~d}^{1} \mathrm{D}+0.025 \mathrm{p}^{2}\left({ }_{2}^{3} \mathrm{P}\right){ }^{3} \mathrm{P}$ & 109567 & 110139 & $1.29 \mathrm{e}-09$ & $1.29 \mathrm{e}-09$ \\
\hline 51 & $4 \mathrm{~d} 5 \mathrm{~d}^{1} \mathrm{G}_{4}$ & 0.91 & 110166 & 110631 & $1.14 \mathrm{e}-09$ & $1.14 \mathrm{e}-09$ \\
\hline 52 & $4 \mathrm{~d} 5 \mathrm{~d}{ }^{1} \mathrm{~S}_{0}$ & $0.85+0.035 \mathrm{p}^{2}\left({ }_{0}^{1} \mathrm{~S}\right){ }^{1} \mathrm{~S}+0.0$ & 113171 & 113551 & $1.47 \mathrm{e}-09$ & $1.40 \mathrm{e}-09$ \\
\hline 53 & $4 \mathrm{~d} 6 \mathrm{p}^{1} \mathrm{D}_{2}^{\circ}$ & $0.51+0.274 \mathrm{~d} 6 \mathrm{p}^{3} \mathrm{~F}^{\circ}+0.124 \mathrm{~d} 6 \mathrm{p}^{3} \mathrm{D}^{\circ}$ & 117113 & 117612 & $6.41 \mathrm{e}-09$ & $7.15 \mathrm{e}-09$ \\
\hline 54 & $4 \mathrm{~d} 6 \mathrm{p}^{3} \mathrm{D}_{1}^{\circ}$ & $0.88+0.034 \mathrm{~d} 6 \mathrm{p}{ }^{1} \mathrm{P}^{\circ}+0.024 \mathrm{~d} 4 \mathrm{f}^{3} \mathrm{D}^{\circ}$ & 117330 & 117801 & $4.23 e-09$ & $4.56 \mathrm{e}-09$ \\
\hline 55 & $4 \mathrm{~d} 6 \mathrm{p}^{3} \mathrm{D}_{2}^{\circ}$ & $0.47+0.444 \mathrm{~d} 6 \mathrm{p}^{3} \mathrm{~F}^{\circ}+0.024 \mathrm{~d} 6 \mathrm{p}^{1} \mathrm{D}^{\circ}$ & 117818 & 118814 & $5.02 \mathrm{e}-09$ & $5.45 \mathrm{e}-09$ \\
\hline 56 & $4 \mathrm{~d} 6 \mathrm{p}^{3} \mathrm{~F}_{2}^{\circ}$ & $\mathbf{0 . 2 1}+0.344 \mathrm{~d} 6 \mathrm{p}^{1} \mathrm{D}^{\circ}+0.324 \mathrm{~d} 6 \mathrm{p}^{3} \mathrm{D}^{\circ}$ & 118309 & 118328 & $5.77 \mathrm{e}-09$ & $6.31 \mathrm{e}-09$ \\
\hline 57 & $4 d 6 p^{3} F_{3}^{\circ}$ & $0.70+0.154 \mathrm{~d} 6 \mathrm{p}^{3} \mathrm{D}^{\circ}+0.074 \mathrm{~d} 6 \mathrm{p}{ }^{1} \mathrm{~F}^{\circ}$ & 118330 & 118849 & $5.43 e-09$ & $5.90 \mathrm{e}-09$ \\
\hline 58 & $4 d 6 p^{3} \mathrm{D}_{3}^{\circ}$ & $0.68+0.184 \mathrm{~d} 6 \mathrm{p}^{3} \mathrm{~F}^{\circ}+0.034 \mathrm{~d} 4 \mathrm{f}^{3} \mathrm{D}^{\circ}$ & 118527 & 119025 & $4.36 \mathrm{e}-09$ & $4.65 \mathrm{e}-09$ \\
\hline 59 & $4 \mathrm{~d} 6 \mathrm{p}^{3} \mathrm{P}_{1}^{\circ}$ & $0.72+0.144 \mathrm{~d} 6 \mathrm{p}^{1} \mathrm{P}^{\circ}+0.044 \mathrm{~d} 4 \mathrm{f}^{3} \mathrm{P}^{\circ}$ & 118988 & & $6.88 \mathrm{e}-09$ & $7.05 \mathrm{e}-09$ \\
\hline 60 & $4 d 6 p^{3} \mathrm{P}_{0}^{\circ}$ & $0.91+0.044 \mathrm{~d} 4 \mathrm{f}^{3} \mathrm{P}^{\circ}$ & 119058 & & $8.12 \mathrm{e}-09$ & $8.39 \mathrm{e}-09$ \\
\hline 61 & $4 d 6 p^{3} F_{4}^{\circ}$ & $0.78+0.094 \mathrm{~d} 4 \mathrm{f}^{3} \mathrm{~F}^{\circ}+0.074 \mathrm{~d} 4 \mathrm{f}^{1} \mathrm{G}^{\circ}$ & 119316 & 119796 & $4.82 \mathrm{e}-09$ & $4.87 \mathrm{e}-09$ \\
\hline 62 & $4 \mathrm{~d} 4 \mathrm{f}^{1} \mathrm{G}_{4}^{\circ}$ & $0.69+0.114 \mathrm{~d} 6 \mathrm{p}^{3} \mathrm{~F}^{\circ}+0.084 \mathrm{~d} 4 \mathrm{f}^{3} \mathrm{H}^{\circ}$ & 119624 & 119976 & $1.35 \mathrm{e}-09$ & $1.32 \mathrm{e}-09$ \\
\hline 63 & $4 d 6 p^{3} \mathrm{P}_{2}^{\circ}$ & $0.82+0.074 \mathrm{~d} 4 \mathrm{f}^{3} \mathrm{P}^{\circ}+0.054 \mathrm{~d} 6 \mathrm{p}^{1} \mathrm{D}^{\circ}$ & 119831 & 120371 & $8.27 \mathrm{e}-09$ & $8.42 \mathrm{e}-09$ \\
\hline 64 & $4 d 6 p^{1} \mathrm{~F}_{3}^{\circ}$ & $0.70+0.114 \mathrm{~d} 4 \mathrm{f}^{1} \mathrm{~F}^{\circ}+0.084 \mathrm{~d} 6 \mathrm{p}^{3} \mathrm{D}^{\circ}$ & 119882 & 120326 & $1.81 \mathrm{e}-09$ & $1.90 \mathrm{e}-09$ \\
\hline 65 & $4 d 4 f^{3} F_{2}^{0}$ & $0.82+0.094 \mathrm{~d} 4 \mathrm{f}^{1} \mathrm{D}^{\circ}$ & 120213 & 120562 & $6.72 \mathrm{e}-10$ & $6.62 \mathrm{e}-10$ \\
\hline 66 & $4 \mathrm{~d} 4 \mathrm{f}^{3} \mathrm{H}_{4}^{\circ}$ & $0.78+0.074 \mathrm{~d} 4 \mathrm{f}^{3} \mathrm{~F}^{\circ}+0.064 \mathrm{~d} 4 \mathrm{f}^{3} \mathrm{G}^{\circ}$ & & & $2.26 \mathrm{e}-09$ & $2.18 \mathrm{e}-09$ \\
\hline 67 & $4 \mathrm{~d} 4 \mathrm{f}^{3} \mathrm{~F}_{3}^{\circ}$ & $0.79+0.074 \mathrm{~d} 4 \mathrm{f}^{3} \mathrm{G}^{\circ}+0.044 \mathrm{~d} 6 \mathrm{p}^{3} \mathrm{~F}^{\circ}$ & 120439 & 120794 & $6.22 \mathrm{e}-10$ & $6.14 \mathrm{e}-10$ \\
\hline 68 & $4 \mathrm{~d} 6 \mathrm{p}^{1} \mathrm{P}_{1}^{\circ}$ & $0.59+0.184 \mathrm{~d} 6 \mathrm{p}^{3} \mathrm{P}^{\circ}+0.144 \mathrm{~d} 4 \mathrm{f}^{1} \mathrm{P}^{\circ}$ & 120545 & 121006 & $3.90 \mathrm{e}-09$ & $3.90 \mathrm{e}-09$ \\
\hline 69 & $4 \mathrm{~d} 4 \mathrm{f}^{3} \mathrm{H}_{5}^{\circ}$ & $0.89+0.034 \mathrm{~d} 4 \mathrm{f}^{3} \mathrm{G}^{\circ}$ & 120670 & 121022 & $3.48 \mathrm{e}-09$ & $3.29 \mathrm{e}-09$ \\
\hline 70 & $4 d 4 f^{3} \mathrm{~F}_{4}^{\circ}$ & $0.70+0.144 \mathrm{~d} 4 \mathrm{f}^{1} \mathrm{G}^{\circ}+0.054 \mathrm{~d} 4 \mathrm{f}^{3} \mathrm{H}^{\circ}$ & 120942 & 121281 & $7.67 e-10$ & $7.56 \mathrm{e}-10$ \\
\hline 71 & $4 \mathrm{~d} 4 \mathrm{f}^{3} \mathrm{H}_{6}^{\circ}$ & 0.94 & 121368 & 121717 & $1.09 \mathrm{e}-08$ & $9.50 \mathrm{e}-09$ \\
\hline 72 & $4 \mathrm{~d} 4 \mathrm{f}^{3} \mathrm{G}_{3}^{\circ}$ & $0.80+0.054 \mathrm{~d} 4 \mathrm{f}^{1} \mathrm{~F}^{\circ}+0.044 \mathrm{~d} 4 \mathrm{f}^{3} \mathrm{~F}^{\circ}$ & 121580 & 122020 & $2.98 \mathrm{e}-10$ & $2.93 \mathrm{e}-10$ \\
\hline 73 & ${ }^{1} \mathrm{D}_{2}^{\circ}$ & $0.78+0.084 \mathrm{~d} 4 \mathrm{f}^{3} \mathrm{~F}^{\circ}+0.034 \mathrm{~d} 4 \mathrm{f}^{3} \mathrm{P}^{\circ}$ & 121675 & 122088 & $5.52 \mathrm{e}-10$ & $5.43 \mathrm{e}-10$ \\
\hline 74 & $4 \mathrm{~d} 4 \mathrm{f}^{3} \mathrm{G}_{4}^{\circ}$ & $0.84+0.064 \mathrm{~d} 4 \mathrm{f}^{3} \mathrm{~F}^{\circ}+0.024 \mathrm{~d} 4 \mathrm{f}^{3} \mathrm{H}^{\circ}$ & 122149 & 122610 & $2.99 \mathrm{e}-10$ & $2.95 \mathrm{e}-10$ \\
\hline 75 & $4 d 4 f^{3} G_{5}^{0}$ & $0.90+0.044 \mathrm{~d} 4 \mathrm{f}^{3} \mathrm{H}^{\circ}$ & 122417 & 122896 & $2.86 \mathrm{e}-10$ & $2.82 \mathrm{e}-10$ \\
\hline 76 & $4 d 4 f^{3} D_{1}^{\circ}$ & $0.82+0.084 \mathrm{~d} 4 \mathrm{f}^{3} \mathrm{P}^{\circ}$ & 122838 & 123341 & $3.93 \mathrm{e}-10$ & $3.84 \mathrm{e}-10$ \\
\hline 77 & $4 \mathrm{~d} 4 \mathrm{f}^{3} \mathrm{D}_{3}^{\circ}$ & $0.50+0.294 \mathrm{~d} 4 \mathrm{f}^{1} \mathrm{~F}^{\circ}+0.054 \mathrm{~d} 4 \mathrm{f}^{3} \mathrm{G}^{\circ}$ & 122876 & 123966 & $3.75 \mathrm{e}-10$ & $3.67 \mathrm{e}-10$ \\
\hline 78 & $4 d 4 f^{3} \mathrm{D}_{2}^{\circ}$ & $0.71+0.144 \mathrm{~d} 4 \mathrm{f}^{3} \mathrm{P}^{\circ}+0.034 \mathrm{~d} 4 \mathrm{f}^{1} \mathrm{D}^{\circ}$ & 122889 & 123405 & $4.05 \mathrm{e}-10$ & $3.96 \mathrm{e}-10$ \\
\hline 79 & $4 \mathrm{~d} 4 \mathrm{f}^{1} \mathrm{~F}_{3}^{\circ}$ & $0.48+0.374 \mathrm{~d} 4 \mathrm{f}^{3} \mathrm{D}^{\circ}+0.054 \mathrm{~d} 6 \mathrm{p}^{1} \mathrm{~F}^{\circ}$ & 123529 & 123310 & $3.64 \mathrm{e}-10$ & $3.56 \mathrm{e}-10$ \\
\hline 80 & $4 \mathrm{~d} 4 \mathrm{f}^{3} \mathrm{P}_{2}^{\circ}$ & $0.69+0.184 \mathrm{~d} 4 \mathrm{f}^{3} \mathrm{D}^{\circ}+0.054 \mathrm{~d} 6 \mathrm{p}^{3} \mathrm{P}^{\circ}$ & 123947 & 124468 & $4.52 \mathrm{e}-10$ & $4.43 e-10$ \\
\hline 81 & $4 \mathrm{~d} 4 \mathrm{f}^{3} \mathrm{P}_{1}^{\mathrm{o}}$ & $0.81+0.094 \mathrm{~d} 4 \mathrm{f}^{3} \mathrm{D}^{\circ}+0.044 \mathrm{~d} 6 \mathrm{p}^{3} \mathrm{P}^{\circ}$ & 124168 & 124687 & $4.63 e-10$ & $4.53 \mathrm{e}-10$ \\
\hline 82 & $4 d 4 f^{3} \mathrm{P}_{0}^{\circ}$ & $0.90+0.044 \mathrm{~d} 6 \mathrm{p}^{3} \mathrm{P}^{\circ}$ & 124313 & 124835 & $4.75 \mathrm{e}-10$ & $4.64 \mathrm{e}-10$ \\
\hline 83 & $4 \mathrm{~d} 4 \mathrm{f}{ }^{1} \mathrm{H}_{5}^{\circ}$ & 0.92 & 125055 & 125439 & $2.72 \mathrm{e}-10$ & $2.63 \mathrm{e}-10$ \\
\hline 84 & $5 \mathrm{p}^{2}\left({ }_{2}^{3} \mathrm{P}\right){ }^{3} \mathrm{P}_{0}$ & $0.87+0.044 \mathrm{~d} 5 \mathrm{~d}^{3} \mathrm{P}$ & 125971 & 125996 & $3.64 \mathrm{e}-10$ & $3.67 \mathrm{e}-10$ \\
\hline 85 & $5 \mathrm{p}^{2}\left({ }_{2}^{1} \mathrm{D}\right){ }^{1} \mathrm{D}_{2}$ & $0.55+0.185 \mathrm{~s} 5 \mathrm{~d}{ }^{1} \mathrm{D}+0.175 \mathrm{p}^{2}\left({ }_{2}^{3} \mathrm{P}\right){ }^{3} \mathrm{P}$ & 126488 & 126561 & $6.75 \mathrm{e}-10$ & $6.81 \mathrm{e}-10$ \\
\hline 86 & $5 \mathrm{p}^{2}\left({ }_{2}^{3} \mathrm{P}\right){ }^{3} \mathrm{P}_{1}$ & $0.88+0.044 \mathrm{~d} 5 \mathrm{~d}^{3} \mathrm{P}$ & 126803 & 126854 & $3.59 \mathrm{e}-10$ & $3.62 \mathrm{e}-10$ \\
\hline 87 & $4 \mathrm{~d} 4 \mathrm{f}{ }^{1} \mathrm{P}_{1}^{\circ}$ & $0.72+0.144 \mathrm{~d} 6 \mathrm{p}^{1} \mathrm{P}^{\circ}+0.035 \mathrm{~s} 5 \mathrm{p}^{1} \mathrm{P}^{\circ}$ & 126865 & 126841 & $4.73 e-10$ & $4.55 \mathrm{e}-10$ \\
\hline 88 & $5 \mathrm{p}^{2}\left({ }_{2}^{3} \mathrm{P}\right){ }^{3} \mathrm{P}_{2}$ & $0.71+0.125 \mathrm{p}^{2}\left({ }_{2}^{1} \mathrm{D}\right){ }^{1} \mathrm{D}+0.055 \mathrm{~s} 5 \mathrm{~d}^{1} \mathrm{D}$ & 128513 & 128600 & $4.01 \mathrm{e}-10$ & $4.05 \mathrm{e}-10$ \\
\hline
\end{tabular}

